\title{
Genetic association of the presenilin-1 regulatory region with early-onset Alzheimer's disease in a population-based sample
}

\author{
Cornelia M van Duijn ${ }^{1}$, Marc Cruts ${ }^{2}$, Jessie Theuns ${ }^{2}$, Geert Van Gassen ${ }^{2}$, \\ Hubert Backhovens ${ }^{2}$, Marleen van den Broeck ${ }^{2}$, Anita Wehnert ${ }^{2}$, Sally Serneels ${ }^{2}$, \\ Albert Hofman ${ }^{1}$ and Christine Van Broeckhoven ${ }^{2}$ \\ ${ }^{1}$ Department of Epidemiology \& Biostatistics, Erasmus University Medical School, Rotterdam, The Netherlands \\ ${ }^{2}$ Department of Molecular Genetics, Flanders Interuniversity Institute for Biotechnology, Laboratory of \\ Neurogenetics, Born-Bunge Foundation, University of Antwerp, Department of Biochemistry, Antwerpen, Belgium
}

\begin{abstract}
Genetic association has been reported between a di-allelic polymorphism in intron 8 of presenilin-1 (PSEN1) and Alzheimer's disease (AD) in some studies but not in others. In a population-based series of 102 patients with early onset $A D$ and 118 community controls we examined whether polymorphisms in linkage disequilibrium with intron 8 of PSEN1 may explain the association. In addition to the intron 8 polymorphism $(P=0.05)$, a promoter polymorphism $(P=0.03)$ and the simple tandem repeat $(S T R)$ polymorphism D14S1028 located upstream of PSEN1 $(P=0.04)$ were found to be marginally significantly associated to AD. When excluding PSEN1 mutation cases $(n=6)$, the intron 8 association was explained by linkage disequilibrium to the dominant PSEN1 mutations. In the non-mutation cases, the weak associations between the polymorphisms in the regulatory region remained. Our study suggests that a polymorphism/mutation in the promoter or regulatory region of PSEN1 rather than the polymorphism in intron 8 of PSEN1 is associated with early onset AD.
\end{abstract}

Keywords: Alzheimer's disease; early-onset; presenilin-1; genetic association

\section{Introduction}

PSEN1 is a gene involved in autosomal dominant forms of early onset Alzheimer's disease (AD). ${ }^{1}$ In addition to the dominant mutations, genetic association was reported between a di-allelic polymorphism in intron 8 of PSEN1 and AD, in which a twofold increase of the

Correspondence: Professor Dr Christine Van Broeckhoven, Molecular Genetics Laboratory, University of Antwerp (UIA), Department of Biochemistry, Universiteitsplein 1, B-2610 Antwerpen, Belgium. Tel: + 323 8202601; Fax: + 323 8202541; E-mail: cvbroeck@uia.ua.ac.be

Received 14 December 1998; revised 23 April 1999; accepted 28 May 1999
11 genotype was observed. ${ }^{2}$ The association was confirmed in a number of case series, ${ }^{3-7}$ but not in others. $^{8-14}$ No evidence was found for an influence of the PSEN1 intron 8 polymorphism on the amount or molecular form of $\beta$ amyloid deposition, one of the main pathological characteristics of $A D$, suggesting the absence of a functional relation to AD. ${ }^{15}$ Until now, there has been little evidence for genetic variability in PSEN1 that could account for the association with the PSEN1 intron 8 polymorphism. ${ }^{16}$ We conducted a study of polymorphisms flanking PSEN1 in a populationbased series of 102 patients with early onset AD and 118 community controls. 
Table 1 Allele and genotype frequencies of polymorphisms in PSEN1 in early-onset AD cases and controls

\begin{tabular}{|c|c|c|c|c|c|c|c|}
\hline \multirow{2}{*}{ Polymorphism } & & & \multicolumn{2}{|c|}{ Cases } & \multicolumn{2}{|c|}{ Controls } & \multirow[b]{2}{*}{$P$ value } \\
\hline & & & $n$ & $\%$ & $n$ & $\%$ & \\
\hline \multirow[t]{5}{*}{ Promoter } & Allele & 1 & 194 & 95 & 209 & 89 & 0.03 \\
\hline & & 2 & 10 & 5 & 25 & 11 & \\
\hline & Genotype & 11 & 93 & 91 & 94 & 80 & 0.04 \\
\hline & & 12 & 8 & 8 & 21 & 18 & \\
\hline & & 22 & 1 & 1 & 2 & 2 & \\
\hline \multirow[t]{5}{*}{ 5'UTR } & Allele & 1 & 168 & 82 & 187 & 83 & 0.75 \\
\hline & & 2 & 38 & 18 & 39 & 17 & \\
\hline & Genotype & 11 & 3 & 3 & 3 & 3 & 0.95 \\
\hline & & 12 & 32 & 31 & 33 & 29 & \\
\hline & & 22 & 67 & 66 & 77 & 68 & \\
\hline \multirow[t]{5}{*}{ Intron 8} & Allele & 1 & 90 & 45 & 127 & 54 & 0.05 \\
\hline & & 2 & 110 & 55 & 107 & 46 & \\
\hline & Genotype & 11 & 26 & 26 & 34 & 29 & 0.03 \\
\hline & & 12 & 38 & 38 & 59 & 50 & \\
\hline & & 22 & 35 & 36 & 24 & 21 & \\
\hline \multirow[t]{5}{*}{ 3'UTR } & Allele & 1 & 172 & 86 & 195 & 84 & 0.57 \\
\hline & & 2 & 28 & 14 & 37 & 16 & \\
\hline & Genotype & 11 & 74 & 74 & 83 & 72 & 0.79 \\
\hline & & 12 & 24 & 24 & 29 & 25 & \\
\hline & & 22 & 2 & 2 & 4 & 3 & \\
\hline
\end{tabular}

\section{Subjects and Methods}

Patients $(n=102)$ were derived from a population-based epidemiological study of early-onset $\mathrm{AD} .{ }^{17}$ Within two areas of the Netherlands, the study aimed at a complete ascertainment of all AD patients in whom the disease onset was at or before the age of 65 years. For this study, the clinical diagnosis of $\mathrm{AD}$ was independently confirmed by two neurologists using a standardised protocol according to the NINCDSADRDA criteria for AD. Family history of dementia addressed all first, second and third degree relatives of the patients. Patients who were known to be related were excluded from the association studies presented here. The mean age at onset of the patients was $56.7 \pm 5.4$ years and the mean attained age at the time of the study was $63 \pm 4.4$ years. Patients were compared to an age-matched control series ( $n=118$; mean age $63 \pm 4.4$ years $)$ that was drawn randomly from the Rotterdam Study. ${ }^{17,18}$ According to the family histories (up to 2 degrees), these subjects were not related. None of the control subjects showed symptoms of dementia and none had cognitive test scores suspect for dementia. ${ }^{17,18}$

All patients were previously subjected to mutation analysis of exons 16 and 17 of the amyloid precursor protein gene (APP) ${ }^{19}$ and all exons of PSEN1 and presenilin-2 (PSEN2). ${ }^{16}$ No APP mutations were found, whereas six patients carried a PSEN1 mutation and one a PSEN2 mutation. ${ }^{16}$ For PSEN2, three polymorphisms in exons 3 and 4 and intron $11^{16}$ and STR marker D1S479 located near PSEN2 ${ }^{20}$ were analysed to exclude the possibility of genetic association. Allele and genotype distributions of PSEN2 polymorphisms were similar in cases and controls. The frequency of the $\varepsilon 4$ allele of the apolipoprotein E gene (APOE), the most important suscepti- bility gene for $\mathrm{AD}$ in the general population, ${ }^{21}$ was 2.3 times increased in patients compared to controls. ${ }^{17}$

In this study, four di-allelic PSEN1 polymorphisms in the promoter region, the 5 untranslated region (UTR), ${ }^{16}$ intron $8^{2}$ and the $3^{\prime}$ UTR, respectively, (this study) were analysed. The 3'UTR polymorphism was detected using PCR primers 3UTR7 (5'-AAACAGTACAGCTATTTCTCATCA-3') and 3UTR8 (5'-GCTTCAACAGCCATTTTACTC-3') to amplify an A to $\mathrm{G}$ polymorphism at nucleotide 952 in the $3^{\prime} \mathrm{UTR}$ of PSEN1. The amplification products were digested with $5 \mathrm{U}$ NlaIII resulting in a constant fragment of $37 \mathrm{bp}$ and 2 alleles of $308 \mathrm{bp}$ (G-allele) and $162+146 \mathrm{bp}$ (A-allele), respectively. For each PCR-RFLP, the longer restriction fragment was assigned allele number 1, whilst the shorter one was assigned allele number 2. Further, linkage disequilibrium with STR polymorphisms flanking PSEN1 was examined (D14S1028, D14S77, D14S1004, D14S43 and D14S61). Alleles for the STR polymorphisms were numbered as in the CEPH Genotype Database (http://www.cephb.fr./cephdb).

The association between early-onset $\mathrm{AD}$ and the polymorphisms studied was assessed using the likelihood ratio test or the Fisher exact test when appropriate. For di-allelic markers, genotype and allele frequencies were compared between cases and controls. For the STR markers, comparisons were restricted to allele frequencies because of the larger number of (rare) genotypes. Linkage disequilibrium was tested using the EH program as described by Terwilliger and Ott. ${ }^{22}$ Since the markers tested were in strong linkage disequilibrium, adjustment for multiple testing is not straightforward, as statistical tests are not independent. In the tables we therefore report exact $P$ values. When the overall likelihood ratio test had a $P$ value of 0.05 or less, the strength of 


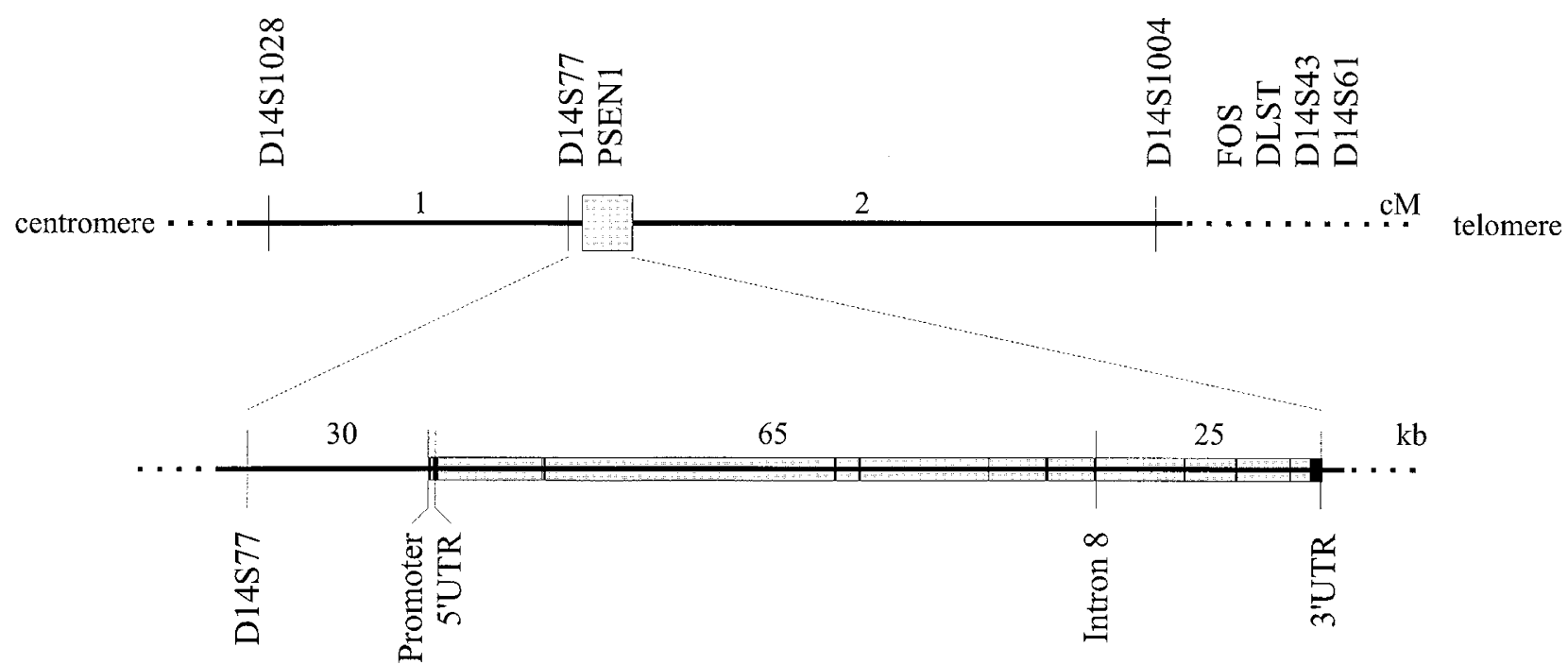

Figure 1 Map of the chromosome 14q24.3 region containing PSEN1. The position of the STR polymorphisms and the $5^{\prime} \rightarrow 3^{\prime}$ orientation of PSEN1 are as published by Cruts et al. ${ }^{26}$ Distances are in centimorgan (cM) according to the Généthon sex averaged genetic map of chromosome $14,{ }^{27}$ or in kilobases $(\mathrm{kb})$ defined by restriction mapping of PSEN $1^{28}$ and YAC fragmentation ${ }^{29}$

association between the alleles or genotypes and early-onset AD was evaluated with the odds ratio (OR) presented with $95 \%$ confidence intervals (CI). Genotype and allele frequencies were in Hardy-Weinberg equilibrium for all markers. Stratified analyses were conducted based on the presence of known PSEN1 mutations ${ }^{16}$ or an APOE $\varepsilon 4$ allele. ${ }^{19}$

\section{Results}

Within the PSEN1 gene, four di-allelic polymorphisms were examined (Table 1$)$. In our population, the allele $(P=0.05)$ and genotype $(P=0.03)$ distributions of the intron 8 polymorphism in patients differed marginally from that in controls. Also, the promoter polymorphism was weakly associated with AD when comparing allele $(P=0.03)$ and genotype $(P=0.05)$ distributions between patients and controls. No differences were observed for the 5'UTR and 3'UTR polymorphisms. When analysing STR markers upstream of PSEN1 (Figure 1), the allele distribution of D14S1028 was different between AD cases and controls $(P=0.04)$. No association was detected with D14S77 located $30 \mathrm{~kb}$ upstream of PSEN1 (Figure 1) (data not shown). Downstream of PSEN1, no association was found with D14S1004 or the more distantly located STRs, D14S43 and D14S61, or the di-allelic polymorphisms in FOS and DLST (Figure 1) (data not shown).

The differences in genotype distributions between cases and controls are explained by increased homozygosity. In some cases an increased frequency was found of the 22 genotype for the intron 8 polymorphism, the 11 genotype for the promoter polymorphism and the 44 genotype for D14S1028. Genotype frequencies were stratified for the presence of mutations in PSEN1 (Table 2). Five of the six patients with a PSEN1 mutation carried the promoter genotype 11 (83\% compared with $80 \%$ in controls), whilst four carried the intron 8 genotype 22 (67\% compared with $21 \%$ in controls; $P=0.02$ ) and D14S1028 genotype 44 (67\% compared with $6 \%$ in controls; $P=0.0002)$. In patients without PSEN1 mutations, the association remained for the promoter genotype 11 (OR indicated a 2.6 fold increase in frequency; 95\% CI 1.1-6.1; $P=0.01$ ) and the D14S1028 genotype 44 (OR indicated a 2.9 fold increase in frequency; 95\% CI 1.1-7.9; $P=0.005)$, but not for the intron 8 polymorphisms. Allele 4 (231 bp) of D14S1028 is in linkage disequilibrium with allele 1 of the promoter polymorphism; all carriers of the 44 genotype were homozygous for allele 1 at the promoter polymorphism. Similar genotype frequencies were found for the promoter and D14S1028 in APOE \&4 carriers and non-carriers (data not shown).

\section{Discussion}

This is the first study to examine several polymorphic markers spanning the whole PSEN1 gene as well as flanking regions. Our study shows association to multiple markers in the region upstream of PSEN1. The finding of an early-onset AD associated haplotype suggests that various patients received the PSEN1 
Table 2 Genotype frequencies in early onset AD cases stratified for the presence of PSEN1 mutations

\begin{tabular}{|c|c|c|c|c|c|c|c|}
\hline \multirow{2}{*}{ Polymorphism } & & & \multicolumn{2}{|c|}{ PSEN1 mutations } & \multicolumn{3}{|c|}{ No PSEN1 mutations } \\
\hline & & & $n$ & $\%$ & $n$ & $\%$ & $P$ value \\
\hline D14S1028 & Genotype & $\begin{array}{r}44 \\
\text { Other }\end{array}$ & $\begin{array}{l}4 \\
2\end{array}$ & $\begin{array}{l}67 \\
33\end{array}$ & $\begin{array}{l}13 \\
77\end{array}$ & $\begin{array}{l}14 \\
86\end{array}$ & 0.05 \\
\hline \multirow[t]{2}{*}{ PSEN1 promoter } & Allele & $\begin{array}{l}1 \\
2\end{array}$ & $\begin{array}{r}11 \\
1\end{array}$ & $\begin{array}{r}92 \\
8\end{array}$ & $\begin{array}{r}181 \\
9\end{array}$ & $\begin{array}{r}95 \\
5\end{array}$ & 0.04 \\
\hline & Genotype & $\begin{array}{l}11 \\
12 \\
22\end{array}$ & $\begin{array}{l}5 \\
1 \\
0\end{array}$ & $\begin{array}{l}83 \\
17 \\
67\end{array}$ & $\begin{array}{r}87 \\
7 \\
1\end{array}$ & $\begin{array}{r}92 \\
7 \\
1\end{array}$ & 0.04 \\
\hline \multirow[t]{2}{*}{ PSEN1 intron 8} & Allele & $\begin{array}{l}1 \\
2\end{array}$ & $\begin{array}{l}4 \\
8\end{array}$ & $\begin{array}{l}33 \\
66\end{array}$ & $\begin{array}{r}84 \\
100\end{array}$ & $\begin{array}{l}46 \\
54\end{array}$ & 0.10 \\
\hline & Genotype & $\begin{array}{l}11 \\
12 \\
22\end{array}$ & $\begin{array}{l}2 \\
0 \\
4\end{array}$ & $\begin{array}{r}33 \\
0 \\
67\end{array}$ & $\begin{array}{l}23 \\
38 \\
31\end{array}$ & $\begin{array}{l}25 \\
41 \\
34\end{array}$ & 0.10 \\
\hline
\end{tabular}

region from a common ancestor, suggesting the presence of a disease related mutation/polymorphism.

In contrast to the study by Wragg et al, ${ }^{2}$ who reported an increased homozygosity of the genotype 11 of the intron 8 polymorphism in late-onset AD patients, we found an increased frequency of genotype 22. The association we detected was for a large part explained by the finding that three of the four patients with the same PSEN1 Ala79Val mutation shared the intron 8 genotype 22 as well as STR polymorphisms flanking PSEN1. This indicates that these patients most likely inherited the mutation from a common ancestor. ${ }^{16}$ Also Sorbi et $a l^{11}$ found evidence for association with the PSEN1 intron 8 polymorphism in patients of families segregating PSEN1 mutations, but not in patients with sporadic forms of AD.

In contrast to the intron 8 association, the associations with the PSEN1 promoter and D14S1028 polymorphisms remained in our study when PSEN1 mutation carriers were excluded. In patients without PSEN1 mutations, a 2.6 fold increase of the 11 genotype for the promoter genotype 11 (95\% CI 1.1-6.1; $P=0.03)$ and a 2.9 increased of the 44 genotype of D14S1028 (95\% CI 1.1.-7.9; $P=0.005)$ were found. It is important to realise that given the marginal level of significance in the overall findings, the findings can be interpreted as possibly false positives. However, findings from molecular biological studies of $\mathrm{AD}$ are supportive of a true relationship.

Exons $1 \mathrm{~A}$ and $1 \mathrm{~B}$ are alternatively used exons and sequence analysis of PSEN1 clones from a hippocampal cDNA library suggested that only exon $1 \mathrm{~A}$ containing transcripts are present in brain. ${ }^{23}$ In accordance with this finding, in our study, genetic association was absent with the polymorphism located in exon $1 \mathrm{~B}^{16}$

We do not know whether the promoter polymorphism has any influence on the expression level of $P S E N 1$. Differential expression of $A P O E$ in brain of AD patients with specific $A P O E$ promoter polymorphisms has been associated with an increased risk for late-onset $\mathrm{AD}$ independent of the $A P O E$ \&4 genotype. ${ }^{24,25}$ Another possibility is that other, not yet identified polymorphisms in the PSEN1 promoter region are responsible for the observed association with PSEN1. In this respect the finding with D14S1028 is important. According to our physical mapping data using yeast artificial chromosomes (YACs), D14S1028 is located upstream of the PSEN1 gene (Figure 1). ${ }^{26}$ With D14S1028 we found the strongest evidence for association in terms of statistical significance: a 2.9 times increased frequency of the genotype 44 $(P=0.005)$. Allele 4 is in linkage disequilibrium with allele 1 of the promoter polymorphism; all carriers of the 44 genotype were homozygous for allele 1 at the promoter polymorphism.

Our data suggest that the association of early-onset AD with PSEN1 may result from polymorphism(s) in the promoter region or regulatory regions upstream of PSEN1. Given the marginal significance, the association remains to be confirmed in an independent sample of patients with early-onset AD. Because of the rarity of the phenotype, such sample was not available to us. Only partial information has been published on the 
PSEN1 promoter sequence ${ }^{23}$ and no studies are available that demonstrate how PSEN1 expression is regulated in different tissues including brain. Our study indicates that such studies may be useful for the understanding of the AD pathogenesis.

\section{Acknowledgements}

This study was made possible by financial support from the Flemish Biotechnology Program (COT-004), Fund for Scientific Research-Flanders (Belgium; FWO-F), DWTC Interuniversity Atrractionpoles (IUAP), EU grant BIOTECH (CT96-0743), the American Health Assistance Foundation (AHAF), the International Alzheimer's Research Foundation (IARF) and grants of the Netherlands Organization for Scientific Research (NWO), The Netherlands Institute for Health Sciences (NIHES), the Hersenstichting Nederland (HsN). We thank Drs Wim Schulte, Teun Tanja, Rob Haaxma, Arie Lameris and Rolf Saan for assisting with case diagnosis and Helen de Bruijn, Micheline de Haes, Jeanette Kamman, Hilda Kornman, Hanneke van Meurs and Caroline Valkenburg for genealogy studies. Marc Cruts is a post-doctoral fellow of the FWO-F. Jessie Theuns and Geert Van Gassen are grantholders of the Institute for Science and Technology (IWT).

\section{References}

1 Sherrington R, Rogaev EI, Liang Y et al: Cloning of a gene bearing mis-sense mutations in early-onset familial Alzheimer's disease. Nature 1995; 375: 754-760.

2 Wragg M, Hutton M, Talbot C et al: Genetic association between intronic polymorphism in presenilin-1 gene and late-onset Alzheimer's disease. Lancet 1996; 347: 509-512.

3 Ezquerra M, Blesa R, Tolosa E et al: The genotype 2/2 of the presenilin-1 polymorphism is decreased in Spanish early-onset Alzheimer's disease. Neurosci Lett 1997; 227: 201-204.

4 Higuchi S, Muramatsu T, Matsushita S, Arai H, Sasaki H: Presenilin-1 polymorphism and Alzheimer's disease. Lancet 1996; 347: 1186-1186.

5 Isoe K, Urakami K, Ji Y, Adachi Y, Nakashima K: Presenilin-1 polymorphism in patients with Alzheimer's disease, vascular dementia and alcohol-associated dementia in Japanese population. Acta Neurol Scand 1996; 94: 326-328.

6 Kehoe P, Williams J, Holmans P et al: Association between a PS-1 intronic polymorphism and late onset Alzheimer's disease. Neuroreport 1996; 7: 2155-2158.

7 Matsushita S, Arai H, Muramatsu T et al: Presenilin-1 polymorphism in Alzheimer's disease and vascular dementia. Exp Neurol 1997; 146: 567-569.

8 Cai X-D, Stanton J, Fallin D et al: No association between the intronic presenilin-1 polymorphism and Alzheimer's disease in clinic and population-based samples. Am J Med Genet (Neuropsy Genet) 1997; 74: 202-203.
9 Perez-Tur J, Wavrant-De Vrieze F, Lambert JC, ChartierHarlin M-C, the Alzheimer's Study Group: Presenilin-1 polymorphism and Alzheimer's disease. Lancet 1996; 347: $1560-1561$.

10 Scott WK, Roses AD, Haines JL: Presenilin-1 polymorphism and Alzheimer's disease. Lancet 1996; 347: $1560-1560$.

11 Sorbi S, Nacmias B, Tedde A et al: Presenilin-1 gene intronic polymorphism in sporadic and familial Alzheimer's disease. Neurosci Lett 1997; 222: 132-134.

12 Tysoe C, Whittaker J, Cairns NJ et al: Presenilin-1 intron 8 polymorphism is not associated with autopsy-confirmed late-onset Alzheimer's disease. Neurosci Lett 1997; 222: 68-69.

13 Singleton AB, Lamb H, Leake A, McKeith IG, Perry RH, Morris CM: No association between an intronic polymorphism in the presenilin-1 gene and Alzheimer's disease. Neurosci Lett 1997; 234: 19-22.

14 Lendon CL, Myers A, Cumming A, Goate AM, St. Clair D: A polymorphism in the presenilin 1 gene does not modify risk for Alzheimer's disease in a cohort with sporadic early onset. Neurosci Lett 1997; 228: 212-214.

15 Mann DM, Pickering-Brown SM, Bayatti NN et al: An intronic polymorphism in the presenilin-1 gene does not influence the amount or molecular form of the amyloid beta protein deposited in Alzheimer's disease. Neurosci Lett 1997; 222: 57-60.

16 Cruts M, van Duijn CM, Backhovens H et al: Estimation of the genetic contribution of presenilin-1 and -2 mutations in a population-based study of presenile Alzheimer disease. Hum Mol Genet 1998; 7: 43-51.

17 van Duijn CM, Farrer LA, Backhovens $\mathrm{H}$ et al: A population-based study of familial Alzheimer's disease: Linkage to chromosome 14,19 and 21. Am J Hum Genet 1994; 55: 714-727.

18 Hofman A, Grobbee DE, de Jong PT, van den Ouweland FA: Determinants of disease and disability in the elderly: the Rotterdam Elderly Study. Eur J Epidemiol 1991; 7: 403-422.

19 van Duijn CM, de Knijff P, Cruts M et al: Apolipoprotein E4 allele in a population-based study of early-onset Alzheimer's disease. Nat Genet 1994; 7: 74-78.

20 Levy-Lahad E, Wijsman EM, Nemens E et al: A familial Alzheimer's disease locus on chromosome 1. Science 1995; 269: 970-973.

21 Strittmatter WJ, Saunders AM, Schmechel D et al: Apolipoprotein E: High-avidity binding to $\beta$-amyloid and increased frequency of type 4 allele in late-onset familial Alzheimer disease. Proc Natl Acad Sci USA 1993; 90 1977-1981.

22 Terwilliger JD, Ott J: Handbook of Human Genetic Linkage. John Hopkins University Press: New York, 1994.

23 Rogaev EI, Sherrington R, Wu C et al: Analysis of the 5 sequence, genomic structure, and alternative splicing of the presenilin-1 gene (PSEN1) associated with early onset Alzheimer's disease. Genomics 1997; 40: 415-424.

24 Lambert JC, Pasquier F, Cottel D, Frigard B, Amouyel P, Chartier-Harlin MC: A new polymorphism in the APOE promoter associated with risk of developing Alzheimer's disease. Hum Mol Genet 1998; 7: 533-540. 
25 Bullido MJ, Artiga MJ, Recuero M et al: A polymorphism in the regulatory region of APOE associated with risk for Alzheimer's dementia. Nat Genet 1998; 18: 69-71.

26 Cruts M, Backhovens H, Wang SY et al: Molecular genetic analysis of familial early-onset Alzheimer's disease linked to chromosome 14q24.3. Hum Mol Genet 1995; 4: 2363-2371.

27 Dib C, Faure S, Fizames C et al: A comprehensive genetic map of the human genome based on 5,264 microsatellites. Nature 1996; 380: 152-154.
28 Theuns J, Cruts M, Del-Favero J et al: Determination of the genomic organization of human presenilin 1 by fiberFISH analysis and restriction mapping of cloned DNA. Mammalian Genome 1999; 10: 410-414.

29 Del-Favero J, Goossens D, Van den Bossche D, Van Broeckhoven C: YAC fragmentation with repetitive and single-copy sequences: detailed physical mapping of the presenilin 1 gene on chromosome 14. Gene 1999; 229: 193-201. 